\title{
Sulfonated Phosphine Ligands in the Ruthenium Catalyzed Biphasic Hydrogenation of Unsaturated Hydrocarbons
}

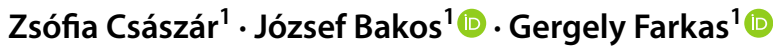

Received: 25 October 2019 / Accepted: 16 February 2020 / Published online: 27 February 2020

(c) The Author(s) 2020

\begin{abstract}
The hydrogenation of monocyclic aromatic hydrocarbons by ruthenium catalysts has been investigated in the presence of sulfonated monophosphine ligands with different stereoelectronic properties under biphasic conditions. The effects of (i) the number of sulfonate groups, (ii) the steric demand of the ligand and (iii) the $\sigma$-donor ability of the phosphorus atom have been investigated in the catalytic reactions. The TEM analysis of the catalytically active systems revealed that in situ formed soluble ruthenium nanoparticles (RuNPs) are responsible for the catalytic turnover. The Ru/sulfonated phosphine system with the properly tuned ligand exhibited high activity $\left(8800 \mathrm{~h}^{-1}\right)$ and selectivity in the hydrogenation of benzene to cyclohexane. Furthermore, the aqueous phase containing RuNPs could be recycled four times without a considerable loss of activity.
\end{abstract}

\section{Graphic Abstract}

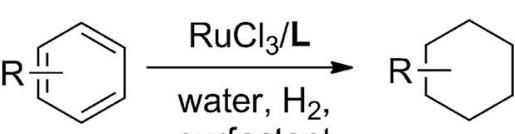
surfactant<smiles>Cc1cc(C)c(S(=O)(=O)O[Na])cc1Oc1cc(S(=O)(=O)O[Na])c(C)cc1C</smiles>

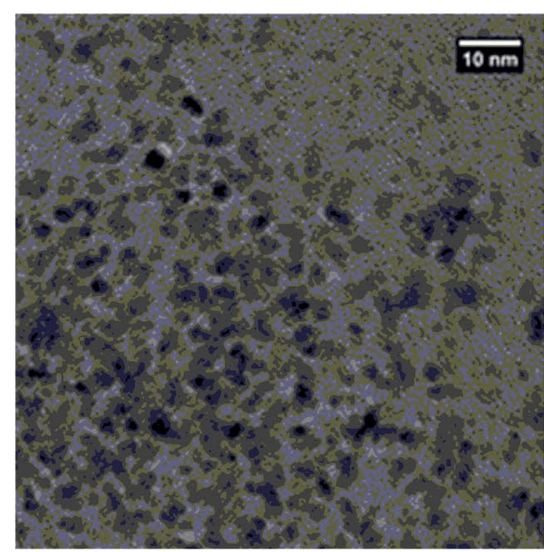

Thorough ligand screening with eight sulfonated monophosphines

Aqueous-organic biphasic catalytic hydrogenation of arenes

High activity and reusability with water-soluble Ru-NPs

Keywords Ruthenium nanoparticle $\cdot$ Sulfonated phosphine $\cdot$ Arene hydrogenation $\cdot$ Biphasic hydrogenation

\section{Introduction}

Transition metal catalyzed reactions performed in aqueous-organic biphasic media represent a fruitful approach to the highly efficient and sustainable synthesis of organic

Gergely Farkas

gerifarkas@almos.uni-pannon.hu

1 Department of Organic Chemistry, University of Pannonia, Egyetem u. 10., Veszprém 8200, Hungary chemicals $[1,2]$. Water is an attractive solvent due to its low cost, easy availability, nontoxic and nonflammable nature [3-5]. Moreover, the application of biphasic catalytic conditions represents a promising alternative for the easy recovery and recycling of the expensive transition metal catalyst. Water-soluble transition metal catalysts can be obtained by combining the corresponding metal precursor with a water-soluble ligand [6]. Amongst these types of ligands sulfonated phosphine sodium-salts can be mentioned as interesting examples due to their structural versatility, high solubility in the aqueous phase and straightforward 
synthesis. The most representative member of this ligand family, trisulfonated triphenylphosphine sodium salt (TPPTS) is industrially applied in the aqueous-organic hydroformylation of propene and butene [7] as well as in the Suzuki-Miyaura coupling of aryl bromides [8]. Despite the impressive progress in the synthesis and catalytic application of sulfonated phosphines in the last decade, a significant number of novel applications have been developed recently. Thus, sulfonated phoshines are extensively used in hydroformylation [9-13], Suzuki-Miyaura coupling [14, 15], hydrogenation of unsaturated esters [16], hydrogenation of levulinic acid to $\gamma$-valerolactone in aqueous media [17, 18], catalytic hydrogenation of bicarbonate [19], hydrogenation of aldehydes [20] or heteroaromatic compounds [21]. A challenging application of transition metal catalysts modified by water-soluble phosphines is the hydrogenation of aromatic hydrocarbons under biphasic conditions.

The complete hydrogenation of aromatic hydrocarbons to cycloparaffins represents a great deal of interest that can mainly be attributed to the growing demand for diesel fuels with low aromatic content $[22,23]$. The aromatic compounds can be responsible for low cetane number of diesel fuels, the high smoke point in jet fuels, and most importantly for the particulate emissions in the exhaust gas. Additionally, the growing concerns about the high carbon dioxide concentration in the atmosphere render fuels with high hydrogen to carbon ratio more suitable [24, 25]. Moreover, cyclohexane, that is produced mainly by the catalytic benzene hydrogenation, is a key intermediate for the synthesis of industrially relevant raw materials such as cyclohexanone, cyclohexanol, caprolactone and caprolactam [26]. Furthermore, cyclohexane is an excellent non-polar solvent and is considered to be greener than $n$-pentane and $n$-hexane [27].

The complete hydrogenation of benzene and its alkylated derivatives to (alkyl)cycloparaffins is realized mainly by heterogeneous supported metal catalysts. It is however, important to note that these processes suffer from several drawbacks. As benzene hydrogenation is strongly exothermic,
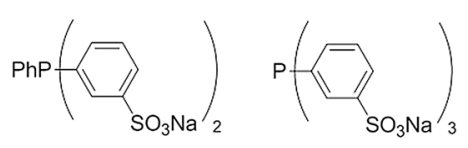

TPPTS

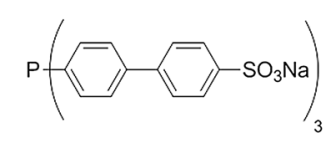

BiphTS

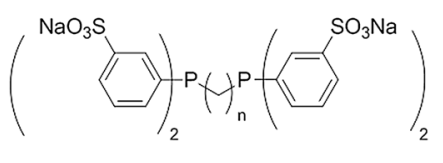

$$
n=2,3,4
$$

Fig. 1 Sulfonated phosphines used in ruthenium catalyzed arene hydrogenation reaction conditions (pressure, temperature, residence time) must precisely be controlled in heterogeneous catalytic reactions to achieve complete conversion. Additionally, heterogeneous catalysts such as supported noble metal catalysts or Raney-Ni, frequently used in benzene hydrogenation, can easily be poisoned by sulfur containing feedstocks [28]. The high pressure and temperature required for the hydrogenation process may also promote several side-reactions as hydrocracking or isomerization leading to alkylated cycloparaffins as byproducts. The difficulties connected to the safe handling of several highly pyrophoric heterogeneous catalyst (Raney-Ni or Ziegler-type catalysts based on triethylaluminium with a nickel or cobalt salt) may also raise serious concerns.

As a result, the development of stable, active, selective and safer catalytic systems for the hydrogenation of aromatic rings is highly desirable. The additional aim of such research is to increase the energy efficiency and to decrease the environmental impact of the hydrogenation process. In this context, the neat aromatic hydrogenation by using water-soluble transition metal catalysts under biphasic conditions represents a fruitful approach towards the synthesis of cycloparaffins. Ruthenium catalysts drew a considerable attention in the field of aromatic hydrogenation as they are highly active and selective catalysts [29] and the precursors are relatively inexpensive compared to the corresponding rhodium or platinum containing compounds [30].

The application of sulfonated phosphines is highly popular in ruthenium catalyzed reactions. Interestingly, however, in arene hydrogenation the use of sulfonated phosphines is less precedented [31-36] and the ligand scope is rather narrow (Fig. 1) despite their promising catalytic properties. In recent years, Papadogianakis and coworkers reported the use of simple Rh/TPPTS complex for the homogeneous hydrogenation of benzene under biphasic conditions [37]. Extremely high catalytic activity $\left(>204,000 \mathrm{~h}^{-1}\right.$ ) could be obtained under optimized conditions. Philippot et al. described the synthesis and catalytic application of ruthenium nanoparticles (RuNPs) stabilized by tetrasulfonated diphosphines of different tether length (Fig. 1) [35]. It has been found that the activity of the catalyst increased with the length of the ligand backbone. Bajaj and coworkers reported on the application of a newly developed sulfonated phosphine, BiphTS [38], in the ruthenium catalyzed hydrogenation of benzene [36]. The in situ prepared catalyst proved to be highly active and could be recycled four times without considerable loss of activity.

Despite the fact that the use of sulfonated phosphines represents an elegant approach for the aqueous-organic biphasic hydrogenation of arenes, no clear interpretation of the steric and electronic factors influencing their catalytic activity has been available yet in such reactions. 
Undoubtedly, through the understanding of these factors the stereoelectronic properties of the ligands could be finetuned to enhance catalytic performance in these catalytic processes.

The present report focuses on the investigation of the stereoelectronic features of sulfonated phosphine ligands in the ruthenium catalyzed arene hydrogenation under biphasic conditions. In order to shed light on the structure-activity relationships we have evaluated a series of sulfonated monophosphine ligands with different stereoelectronic properties. Specifically, eight mono-, di- and trisulfonated systems were used to study (i) the effect of sulfonation degree, (ii) the influence of electron-donating substituents and (iii) the steric demand of the ligand on catalytic activity (Fig. 2).

\section{Results and Discussion}

\subsection{Characterization of the Phosphine Ligands}

Sulfonated monophosphine ligands 1-3 (Fig. 2) with different stereoelectronic properties have been used to evaluate their catalytic properties in the aqueous biphasic hydrogenation of aromatic hydrocarbons. Ligands 1-3 were synthesized according to the literature procedures [39-42]. In order to rationalize their catalytic behavior we characterized their stereoelectronic nature. Ligand sets $\mathbf{1}, \mathbf{2}$ and $\mathbf{3}$ differ in their sulfonation degree that strongly affects their steric and electronic properties. The sulfonate group can be identified as an electron withdrawing substituent, therefore the electron donating ability of the phosphine is reduced by enhancing the number $-\mathrm{SO}_{3}{ }^{-}$substituents [43]. Additionally, the introduction of a sulfonate group in the meta

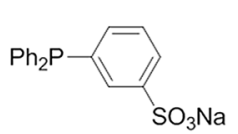

$1 a$

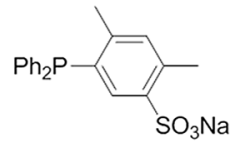

1b

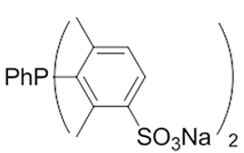

$2 \mathrm{a}$

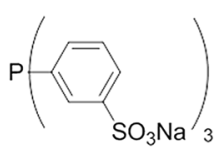

$3 a$

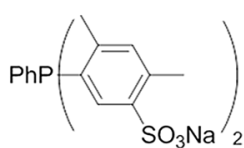

$2 b$

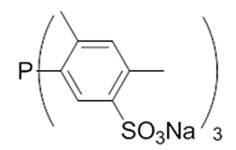

$3 b$

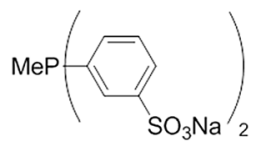

2c

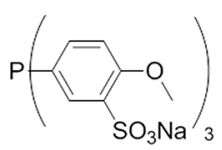

$3 c$
Fig. 2 Ligands used in the ruthenium catalyzed hydrogenation of arenes position increases the Tolman cone angle [44] significantly (eg. 1a vs. 3a, Table 1) [45, 46]. It is therefore not surprising that $o$-methyl substituents even more strongly affect the steric demand of the ligands [45]. In compounds with ortho- or diortho-substituted rings, the Tolman cone angle is drastically increased compared to the parent sulfonated phosphines [47]. (It is interesting to note that the effect of their increased steric demand on their catalytic properties is documented in other homogeneous catalytic reactions [48, 49].) As the steric congestion around the phosphorus is significantly increased, it is reasonable to assume that in these cases the lone pair of the phosphorus atom is less available to coordination. It is also important to mention that ligands with $p$-substituents show no significant difference in the cone angles compared to their unsubstituted analogues [50]. Ligand $\mathbf{2 c}$ with methyl-substituent connected directly to phosphorus is assumed to have smaller cone angle than other phosphines presented in this study.

A simple way of evaluating the $\sigma$-donor ability of the phosphorus functionalities is by measuring the magnitude of the ${ }^{1} J\left({ }^{77} \mathrm{Se}-{ }^{31} \mathrm{P}\right)$ coupling constant in the ${ }^{77} \mathrm{Se}$ isotopomer of the corresponding phosphine-selenide [51, 52]. This value is roughly inversely proportional to the basicity of the phosphine. Thus, to evaluate the electronic nature of the ligands we have synthesized their selenides in the reaction of the phosphines with elemental selenium. The corresponding ${ }^{1} J\left({ }^{77} \mathrm{Se}-{ }^{31} \mathrm{P}\right)$ coupling constants are summarized in Table 1. As expected, (i) the introduction of sulfonate substituents decreased the basicity (eg. ligands 1a, and 3a), (ii) the presence of methyl or methoxy groups increased the $\sigma$-donor character of the ligands. Enhanced $\sigma$-donor ability makes the phosphorus lone pair more available to coordination to the transition metal.

\subsection{Catalytic Hydrogenations}

The catalytic activity of ruthenium catalysts modified by water-soluble ligands 1-3 was studied in the aqueous biphasic hydrogenation of aromatic hydrocarbons and several olefins. The Ru/sulfonated phosphine system was synthesized in situ, by simply mixing the corresponding ligand with $\mathrm{RuCl}_{3} \cdot 3 \mathrm{H}_{2} \mathrm{O}$ precursor in water. At first, the ligands were screened at a phosphine/ruthenium molar ratio of 4 , at $120{ }^{\circ} \mathrm{C}$ and 50 bar $\mathrm{H}_{2}$ pressure in the hydrogenation of neat benzene under biphasic conditions using non-ionic surfactant Brij-L4, according to literature procedure [36].

In the first set of experiments, the effect of the ligands' structure was evaluated in the catalytic reaction. The results achieved by using ligands 1-3 are compiled in Table 2. Catalysts modified with sterically less demanding and/or more basic ligands (1a, 1b, 2c, 3c) resulted in very low turnover (entries 1 and 8) or no catalytic activity (entries 2 and 5). In contrast, sulfonated phosphines with considerable steric 
Table 1 Cone angles of the ligands and the ${ }^{1} J\left({ }^{31} \mathrm{P},{ }^{77} \mathrm{Se}\right)$ coupling constants $[\mathrm{Hz}]$ observed for their selenides $(\mathrm{L}(\mathrm{Se}))$

\begin{tabular}{lll}
\hline Ligand $(\mathrm{L})$ & Cone angle $\left(^{\circ}\right)$ & $\begin{array}{l}{ }^{1} J\left({ }^{31} \mathrm{P},{ }^{77} \mathrm{Se}\right) \text { coupling } \\
\text { constant of } \mathrm{L}(\mathrm{Se})[\mathrm{Hz}]^{\mathrm{c}}\end{array}$ \\
\hline 1a & $151[45]$ & 695.6 \\
1b & - & 670.5 \\
2a & - & 658.7 \\
2b & - & 663.8 \\
2c & - & 677.3 \\
3a & $166^{\mathrm{a}}[45]$ & 707.1 \\
3b & 196 or $210[48]$ & 660.9 \\
3c & $\sim 166^{\mathrm{b}}$ & 681.4 \\
\hline
\end{tabular}

${ }^{\mathrm{a}}$ The cone angle of ligand 3a (TPPTS) has been proposed in a wide range (from $129^{\circ}$ to $178^{\circ}$ ) [46]

${ }^{\mathrm{b}}$ Approximation based on the fact that $p$-substituents do not influence the cone angle

${ }^{\mathrm{c}}$ The NMR spectra were recorded in $\mathrm{D}_{2} \mathrm{O}$ at $25^{\circ} \mathrm{C}$

demand (2a, $\mathbf{2 b}, \mathbf{3 b})$ or decreased $\sigma$-donor ability (3a) formed highly active catalysts (entries 3, 4, 7 and 6, respectively) with ruthenium.

Based on these results and literature findings [33] we decided to investigate the nature of the catalytically active species in the case of ligands $\mathbf{2} \mathbf{a}-\mathbf{b}$ and $\mathbf{3 a} \mathbf{a}-\mathbf{b}$ providing high activity. Initially, control experiments were performed in the presence of mercury under the same conditions. Basically no conversion could be observed in either case suggesting that the catalytically active species are not homogeneous complexes. In the next experiments, the catalytic reaction was repeated with ligands $\mathbf{3 a}$ and $\mathbf{b}$ without addition of mercury to check the reproducibility of the reaction. The catalytic systems modified with $\mathbf{3 a}$ and $\mathbf{b}$ provided similar results in the control experiments, 39 and $>99 \%$ conversions could be achieved, respectively. Using these reaction mixtures, samples were taken from the aqueous phase and analyzed by transmission electron microscopy (TEM). The TEM analysis revealed the presence of well dispersed ruthenium nanoparticles in the aqueous phase. Interestingly, the size distribution and the mean diameter of the nanoparticles formed in the two systems were nearly identical despite the significant difference in their catalytic activity. This suggests that the remarkable differences in their catalytic properties can be correlated to the stereoelectronic features of the phosphine ligands used (Fig. 3).

In other words, high catalytic activity and nanoparticle formation could be achieved with sterically more demanding sulfonated phosphines. This also suggests that ligands with less steric demand or with higher basicity do not facilitate nanoparticle formation under catalytic conditions or simply function as catalyst poisons through a strong coordination to the surface of the nanoparticles. The first case is corroborated by the fact that sterically more demanding phosphines [53-55] or ligands with more negative charge [56-58] form less stable or coordinatively unsaturated complexes due to interligand repulsions and thus may facilitate nanoparticle formation. Consequently, sterically less demanding ligands with stronger $\sigma$-donor ability can stabilize homogeneous complexes more effectively. The second possibility is the consequence of the fact that phosphines with strong coordinating ability block the catalytically active sites of the nanoparticle preventing the coordination of the substrate [59]. However, it cannot be excluded that both of these phenomena play an

Table 2 Screening of sulfonated phosphines in the hydrogenation of benzene under biphasic conditions

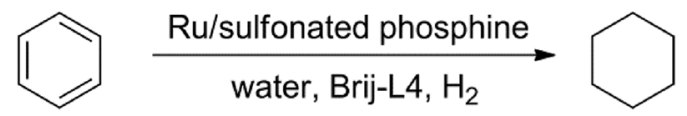

\begin{tabular}{lll}
\hline Entry & Ligand & Conversion (\%) \\
\hline 1 & $\mathbf{1 a}$ & 2 \\
2 & $\mathbf{1 b}$ & 0 \\
3 & $\mathbf{2 a}$ & 60 \\
4 & $\mathbf{2 b}$ & 56 \\
5 & $\mathbf{2 c}$ & 0 \\
6 & $\mathbf{3 a}$ & 31 \\
7 & $\mathbf{3 b}$ & $>99$ \\
8 & $\mathbf{3 c}$ & 1 \\
\hline
\end{tabular}

Reaction conditions: $0.011 \mathrm{mmol}$ of $\mathrm{RuCl}_{3} \cdot 3 \mathrm{H}_{2} \mathrm{O}, 0.044 \mathrm{mmol}$ of sulfonated phosphine in $15 \mathrm{~mL}$ of water. Brij-L4: $11 \mathrm{mmol} / \mathrm{L}$, benzene/Ru molar ratio: 2000 , pressure: 50 bar, temperature: $120^{\circ} \mathrm{C}$, reaction time: $1 \mathrm{~h}$. Conversion has been determined by GC 
important role in reduced catalytic activity. Nevertheless, the application of phosphines with considerable steric bulk $(\mathbf{2 a}, \mathbf{2} \mathbf{b}$ and $\mathbf{3 b}$ ) resulted in the formation of highly active ruthenium catalysts. In contrast, ligands $\mathbf{1 a}, \mathbf{1 b}, \mathbf{2 c}$ and $\mathbf{3 c}$ are possibly too basic and not hindered enough to promote the formation of catalytically active nanoparticles. Finally, even if sterically not hindered, ligand 3a provided an intermediate conversion ( $31 \%$, Table 2 , entry 6 ) that can be due to its low $\sigma$-donor ability $\left({ }^{1} J\left({ }^{31} \mathrm{P},{ }^{77} \mathrm{Se}\right)=707.1 \mathrm{~Hz}\right.$, Table 1).

Encouraged by the catalytic results achieved with ligand $\mathbf{3 b}$, we performed further catalytic tests to obtain a deeper insight into the optimal working conditions of the catalytic system (Table 3 ). The conversion remained $>99$ while decreasing the temperature from 120 to $60^{\circ} \mathrm{C}$. At $50{ }^{\circ} \mathrm{C}$, however, the activity drastically decreased to $17 \%$. Likewise, decreasing the $\mathrm{L} / \mathrm{Ru}$ molar ratio resulted in a decreased turnover. It is, however, important to note that a TOF value of $\sim 8800 \mathrm{~h}^{-1}$ could be obtained at $120^{\circ} \mathrm{C}$ at a substrate/catalyst molar ratio of 6000 .

The catalyst $\mathrm{Ru} / \mathbf{3 b}$ was also assessed in the hydrogenation of more challenging aromatic substrates as well as in the hydrogenation of several alkenes (Table 4). Amongst aromatic hydrocarbons the highest turnover frequency could be obtained with benzene as a substrate. Lower TOF values were achieved with different alkyl-benzenes. The number and the length of the alkyl substituents strongly affected the activity. Alkenes could readily be hydrogenated under the conditions applied.

The main purpose of using water-soluble phosphines in the biphasic hydrogenation reactions is the easy separation
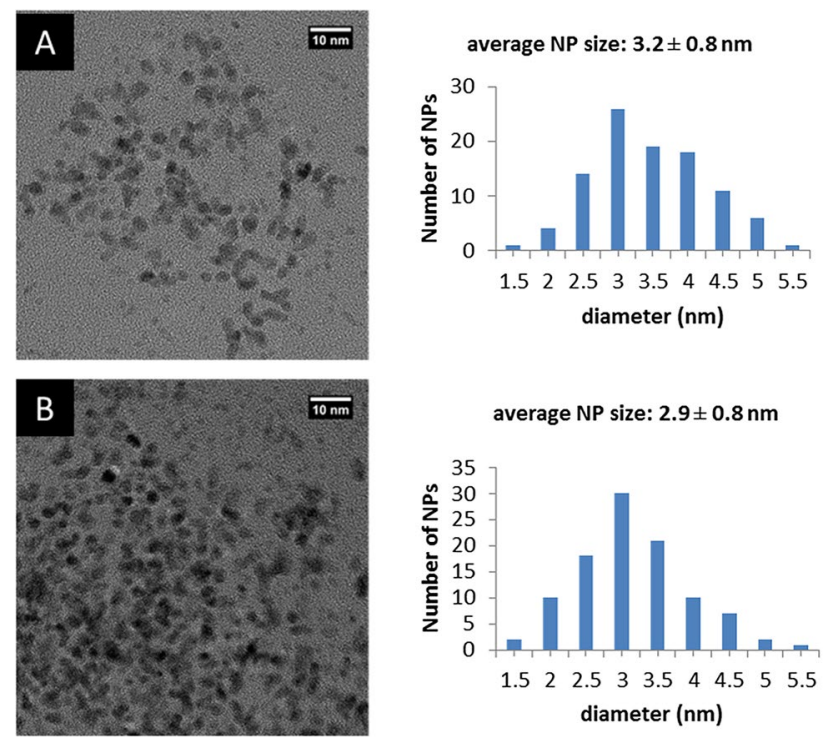

Fig. 3 TEM images and size distributions of RuNPs formed in the presence of ligands $\mathbf{3 a}(\mathbf{a})$ and $\mathbf{3 b}(\mathbf{b})$ of the aqueous phase containing the catalysts from the product and its recycling to the next catalytic run. In the next set of experiments the recycling of the catalyst was investigated with benzene/Ru molar ratio of 8000 at $80{ }^{\circ} \mathrm{C}$ and 50 bar pressure using Brij-L4 as non-ionic detergent. After each catalytic run the upper organic layer of the reaction mixture was separated and the lower aqueous layer was recycled. The catalyst was reused three times with a marginal drop of its activity. The conversion decreased from 20 to $18 \%$ during the four runs indicating that the catalyst can be reused without significant deactivation or leaching from the aqueous to the organic phase (Diagram 1). Ligand $\mathbf{3 b}$ with weak coordination ability promotes the formation of ruthenium nanoparticles and may contribute to their stabilization. The careful stereoelectronic fine-tuning of the phosphine ligand led to a highly active and recyclable in situ formed catalysts in the hydrogenation of aromatic hydrocarbons. The utilization of this strategy in the hydrogenation of heteroatom-containing aromatic compounds is currently in progress.

\section{Conclusion}

Several water-soluble phosphines were characterized and tested in the biphasic aqueous-organic hydrogenation of aromatic hydrocarbons. It has been shown that the steric and electronic properties of the ligands strongly influence the activity of the catalytic system. Water-soluble phosphines with considerable steric demand or low basicity promoted the formation of ruthenium nanoparticles under catalytic conditions. These ligands proved to be labile enough to ensure the binding of the substrate to certain sites on the nanoparticle surface and at the same time they were able to facilitate efficient recycling of the catalyst. Consequently, this study shows the high potential of stereoelectronic finetuning in biphasic nanoparticle chemistry which we believe can be a fruitful approach in other types of catalytic reactions to achieve high activity, selectivity and successful recovery of the catalyst.

\section{Experimental}

\subsection{General Experimental Details}

All synthetic manipulations were carried out under argon using Schlenk techniques. Solvents were purified, dried and deoxygenated by standard methods. Sulfonated phosphines 1a-b, 2a-b, 2d and 3a-c were synthesized according to the literature procedures [39-42]. All other starting materials were purchased from Aldrich. 
Table 3 Hydrogenation of benzene with $\mathrm{Ru} / \mathbf{3 b}$ catalyst at different reaction conditions

\begin{tabular}{llll}
\hline Entry & Temperature $\left({ }^{\circ} \mathrm{C}\right)$ & $\mathrm{L} / \mathrm{Ru}$ & Conversion $(\%)$ \\
\hline 1 & 40 & 4 & 0 \\
2 & 50 & 4 & 17 \\
3 & 60 & 4 & $>99$ \\
4 & 80 & 4 & $>99$ \\
5 & 120 & 4 & $>99$ \\
$6^{\mathrm{a}}$ & 120 & 4 & $>99$ \\
7 & 120 & 2 & 48 \\
8 & 120 & 6 & $>99$ \\
$9^{\mathrm{b}}$ & 120 & 4 & 49 \\
\hline
\end{tabular}

Reaction conditions: $0.011 \mathrm{mmol}$ of $\mathrm{RuCl}_{3} \cdot 3 \mathrm{H}_{2} \mathrm{O}$, the desired amount of sulfonated phosphine in $15 \mathrm{~mL}$ of water. Brij-L4: $11 \mathrm{mmol} / \mathrm{L}$, benzene/Ru molar ratio: 2000, reaction time: $1 \mathrm{~h}$. Conversion has been determined by GC

${ }^{a}$ Without using Brij-L4

${ }^{\mathrm{b}}$ Benzene/Ru molar ratio: 6000

Table 4 Aqueous biphasic hydrogenation of several unsaturated (aromatic and aliphatic) hydrocarbons to the corresponding alkanes

Entry Conversion (\%)

Reaction conditions: $0.011 \mathrm{mmol}$ of $\mathrm{RuCl}_{3} \cdot 3 \mathrm{H}_{2} \mathrm{O}, 0.044 \mathrm{mmol}$ of sulfonated phosphine in $15 \mathrm{~mL}$ of water. Brij-L4: $11 \mathrm{mmol} / \mathrm{L}$, benzene/ Ru molar ratio: 2000 , pressure: 50 bar, temperature: $120{ }^{\circ} \mathrm{C}$, reaction time: $1 \mathrm{~h}$. Conversion has been determined by GC

\subsection{Characterization Techniques}

${ }^{31} \mathrm{P}\left\{{ }^{1} \mathrm{H}\right\}$ NMR measurements were carried out on a Bruker Avance 400 spectrometer (NMR Laboratory, University of Pannonia) operating at $161.98 \mathrm{MHz}$. Samples for TEM analyses were prepared by slow evaporation of a drop of colloidal aqueous solution deposited onto lacey carboncovered copper grids. Transmission electron microscopy analyses were performed at the Nanolab, University of Pannonia. TEM images were obtained with an FEI Talos F200X transmission electron microscope (equipped with $\mathrm{X}$-FEG electron source and Super-X energy disperse $\mathrm{X}$-ray spectrometer) working in parallel illumination (TEM) mode and scanning transmission (STEM) mode. The acceleration voltage was $200 \mathrm{kV}$. TEM brigth field, HRTEM, and STEM images, chemical analysis and elemental maps were taken during the measurements. Statistical size distribution and the mean diameter of the nanoparticles were obtained by the manual analysis of the TEM micrographs by using ImageJ software.

\subsection{Synthesis of Phosphine-selenides}

The selenides were synthesized in $\mathrm{D}_{2} \mathrm{O}$ in the reaction of the corresponding phosphine and elemental selenium at room temperature or in the case of ligands $\mathbf{2 a}-\mathbf{c}$ and $\mathbf{3 b}$ at $90{ }^{\circ} \mathrm{C}$. The reaction mixtures were stirred for $8 \mathrm{~h}$, filtered and then analyzed by NMR. (The product selenides were not isolated or purified due to the high toxicity of elemental selenium.)

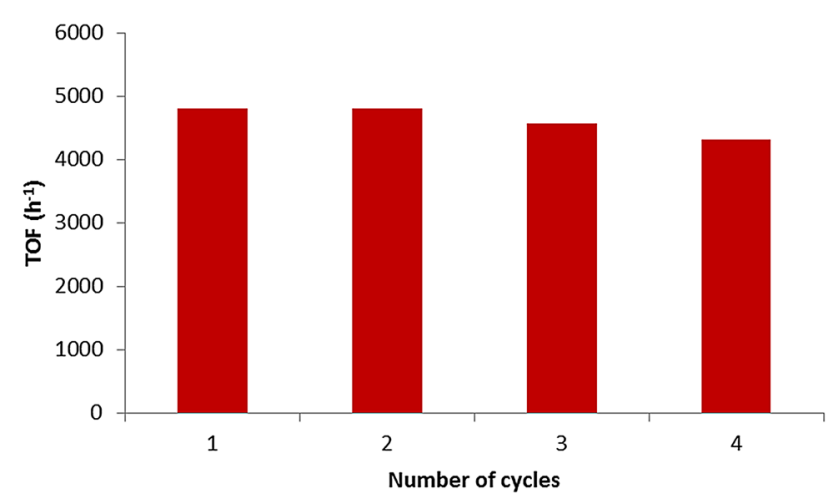

Diagram 1 Recycling of catalyst $\mathrm{Ru} / \mathbf{3 b}$. Reaction conditions: $0.011 \mathrm{mmol}$ of $\mathrm{RuCl}_{3} \cdot 3 \mathrm{H}_{2} \mathrm{O}, 0.044 \mathrm{mmol}$ of sulfonated phosphine in $15 \mathrm{~mL}$ of water. Brij-L4: $11 \mathrm{mmol} / \mathrm{L}$, benzene/Ru molar ratio: 8000, pressure: 50 bar, temperature: $80{ }^{\circ} \mathrm{C}$, reaction time: $1 \mathrm{~h}$. Conversion has been determined by GC, it is $<20 \%$ in each case. TOF has been calculated as moles of double bonds hydrogenated per moles of $\mathrm{Ru}$ per hour 


\subsection{Catalytic Hydrogenation}

A mixture of $\mathrm{RuCl}_{3} \cdot 3 \mathrm{H}_{2} \mathrm{O}$ and the water-soluble phosphine in $15 \mathrm{~mL}$ of water was stirred for $10 \mathrm{~min}$ and Brij-L4 was added to the mixture. (The water used in the catalytic experiments was doubly distilled and thoroughly deoxygenated by argon bubbling and sonication.) The resulting solution and the unsaturated hydrocarbon were charged into a $100 \mathrm{~mL}$ stainless steel autoclave equipped with a glass inlet and a robust magnetic stirring bar. The reactor was then flushed with argon, pressurized with $\mathrm{H}_{2}$ and brought to the desired temperature. The reaction was initiated by stirring (1200 rpm). After the reaction stirring was stopped, the reactor was cooled down with an external water-cooling system and then carefully depressurized. The composition of the upper layer was determined with GC using an Agilent 7820A, equipped with a Supelcowax 10 fused silica capillary column $(30 \mathrm{~m} \times 0.25 \mathrm{~mm}$, film thickness $=0.25 \mu \mathrm{m}$, carrier gas: $\mathrm{N}_{2}$ at $1.14 \mathrm{~mL} / \mathrm{min}$ ) or an SPB-1 capillary column $(30 \mathrm{~m} \times 0.25 \mathrm{~mm}$, film thickness $=0.25 \mu \mathrm{m}$, carrier gas: $\mathrm{N}_{2}$ at $200 \mathrm{kPa}$ ), a split/splitless injector at $250{ }^{\circ} \mathrm{C}$ and a FID at $250{ }^{\circ} \mathrm{C}$. The chromatography method using the Supelcowax column for the determination of the conversion of benzene, toluene, ethylbenzene, $m$-xylene and 1,3,5-trimethylbenzene consists of $5 \mathrm{~min}$ at $50{ }^{\circ} \mathrm{C}$ and a ramp of $5{ }^{\circ} \mathrm{C} \mathrm{min}^{-1}$ to $200{ }^{\circ} \mathrm{C}$. Retention times are $6.1 \mathrm{~min}$ for cyclohexane and $8.2 \mathrm{~min}$ for benzene, $8.2 \mathrm{~min}$ for methylcyclohexane and $11.6 \mathrm{~min}$ for toluene, $8.6 \mathrm{~min}$ for ethylcyclohexane and $13.1 \mathrm{~min}$ for ethylbenzene, $7.5 \mathrm{~min}$ for 1,3-dimethylcyclohexanes and $13.3 \mathrm{~min}$ for $m$-xylene, $8.1 \mathrm{~min}$ for 1,3,5-trimethylcyclohexanes and $16.3 \mathrm{~min}$ for 1,3,5-trimethylbenzene. The same column was used for the determination of the conversion of cyclohexene and cyclooctene at $30{ }^{\circ} \mathrm{C}$ constant temperature. Retention times are 8.6 min for cyclohexane and $10.1 \mathrm{~min}$ for cyclohexene, $21.4 \mathrm{~min}$ for cyclooctane and $24.6 \mathrm{~min}$ for cyclooctene. The SPB column was used for the determination of the conversion of 1-octene at $30{ }^{\circ} \mathrm{C}$ constant temperature. The retention times are $6.9 \mathrm{~min}$ for 1-octene and $7.6 \mathrm{~min}$ for octane. Conversions were calculated as the following: the peak area of the product was divided by the sum of the peak areas of the product and the substrate. TOF values have been calculated as moles of double bonds hydrogenated per moles of $\mathrm{Ru}$ per hour. In the mercury poisoning tests $300 \mathrm{mg}$ of $\mathrm{Hg}$ $(\sim 1.5 \mathrm{mmol})$ was used.

Acknowledgements Open access funding provided by University of Pannonia (PE). We thank Mr Béla Édes for skillful assistance in analytical measurements and synthetic experiments. The research was supported by the project GINOP-2.3.2-15-2016-00053. TEM studies were performed at the electron microscopy laboratory of the University of Pannonia, established using Grant No. GINOP-2.3.3-15-2016-0009 from the European Structural and Investments Funds and the Hungarian Government.

\section{Compliance with Ethical Standards}

Conflict of interest The authors declare that there are no conflicts of interest regarding the publication of this paper.

Open Access This article is licensed under a Creative Commons Attribution 4.0 International License, which permits use, sharing, adaptation, distribution and reproduction in any medium or format, as long as you give appropriate credit to the original author(s) and the source, provide a link to the Creative Commons licence, and indicate if changes were made. The images or other third party material in this article are included in the article's Creative Commons licence, unless indicated otherwise in a credit line to the material. If material is not included in the article's Creative Commons licence and your intended use is not permitted by statutory regulation or exceeds the permitted use, you will need to obtain permission directly from the copyright holder. To view a copy of this licence, visit http://creativecommons.org/licenses/by/4.0/.

\section{References}

1. Cornils B, Herrmann WA (eds) (2004) Aqueous-phase organometallic catalysis: concepts and applications, 2nd edn. Wiley, Weinheim

2. Joó F (ed) (2010) Biphasic catalysis—homogeneous. https://doi. org/10.1002/0471227617.eoc035.pub2

3. Li CJ, Chen L (2006) Chem Soc Rev 35:68-82

4. Chanda A, Fokin VV (2009) Chem Rev 109:725-748

5. Zhou F, Hearne Z, Li CJ (2019) Curr Opin Green Sustain Chem 18:118-123

6. Pinault N, Bruce DW (2003) Coord Chem Rev 241:1-25

7. Kuntz EG (1975) Rhône-Poulenc Recherces Pat. 2.314.910

8. Dupuis C, Adiey K, Charruault L, Michelet V, Savignac M, Genet JP (2001) Tetrahedron Lett 42:6523-6526

9. Jagtap SA, Monflier E, Ponchel A, Bhanage BM (2017) Mol Catal 436:157-163

10. Peral D, Herrera D, Real J, Flor T, Bayón JC (2016) Catal Sci Technol 6:800-808

11. Zhao Y, Liu Y, Wei J, Fu H, Zheng X, Yuan M, Li R, Chen H (2018) Catal Lett 148:438-442

12. Baricelli PJ, Rodriguez M, Melean LG, Alonso MM, Borusiak M, Rosales M, Gonzalez B, de Oliveira KCB, Gusevskaya EV, dos Santos EN (2015) Appl Catal A 490:163-169

13. Baricelli PJ, Alonso MM, Rosales M (2018) Catal Lett 148:1150-1161

14. Zábranský M, Císařová I, Štěpnička P (2018) Organometallics 37:1615-1626

15. Ge J, Jiang J, Yuan C, Zhang C, Liu M (2017) Tetrahedron Lett 58:1142-1145

16. Stathis P, Stavroulaki D, Kaika N, Krommyda K, Papadogianakis G (2017) Appl Catal B 209:579-590

17. Moustani C, Anagnostopoulou E, Krommyda K, Panopoulou C, Koukoulakis KG, Bakeas EB, Papadogianakis G (2018) Appl Catal B 238:82-92

18. Krommyda K, Panopoulou C, Moustani C, Anagnostopoulou E, Makripidi K, Papadogianakis G (2019) Catal Lett 149:1250-1265 
19. Sordakis K, Guerriero A, Bricout H, Peruzzini M, Dyson PJ, Monflier E, Hapiot F, Gonsalvi L, Laurenczy G (2015) Inorg Chim Acta 431:132-138

20. Kokkinos NC, Nikolaou N, Psaroudakis N, Mertis K, Mitkidou S, Mitropoulos AC (2015) Catal Today 247:132-138

21. Páez DE, Andriollo A, Morfes G (2015) Catal Today 247:139-146

22. IARC e International Agency for Research on Cancer and World Health Organization (2013) IARC monographs on the evaluation of carcinogenic risks to humans. In: Diesel and gasoline engine exhaust and some nitroarenes, vol 105

23. IARC e International Agency for Research on Cancer and World Health Organization (2012) IARC monographs on the evaluation of carcinogenic risks to humans. In: Diesel and gasoline engine exhaust and some nitroarenes, vol 105

24. Srivastava SP, Hancsok J (2014) Fuels and fuel-additives. Wiley, Hoboken

25. Hancsok J, Visnyei O, Hollo A, Leveles L, Thernesz A, Varga G, Valyon J (2019) Renew Energy 142:239-248

26. Tinge JT (2016) Cyclohexane oxidation: history of transition from catalyzed to noncatalyzed. In: Stahl SS, Alsters PL (eds) Liquid phase aerobic oxidation catalysis: industrial applications and academic perspectives. Wiley, Weinheim, pp 33-39

27. Byrne FP, Jin S, Paggiola G, Petchey THM, Clark J, Farmer TJ, Hunt AJ, McElroy CR, Sherwood J (2016) Sustain Chem Process 4:7

28. Weissermel K, Arpe HJ (eds) (2003) Industrial organic chemistry, 4th edn. Wiley, Weinheim

29. Dixneuf PH, Bruneau C (eds) (2014) Ruthenium in catalysis. Springer, Cham

30. Tschan MJL, Diebolt O, van Leeuwen PWNM (2014) Top Catal 57:1054-1065

31. Ellis DJ, Dyson PJ, Parker DG, Welton T (1999) J Mol Catal A 150:71-75

32. Parmar DU, Bhatt SD, Bajaj HC, Jasra RV (2003) J Mol Catal A 202:9-15

33. Dyson PJ, Ellis DJ, Laurenczy G (2003) Adv Synth Catal 345:211-215

34. Suárez T, Guzmán A, Fontal B, Reyes M, Bellandi F, Contreras RR, Cancines P, León G, Rojas L (2006) Transit Met Chem $31: 176-180$

35. Guerrero M, Roucoux A, Denicourt-Nowicki A, Bricout H, Monflier E, Collière V, Fajerwerg K, Philippot K (2012) Catal Today 183:34-41

36. Dabbawala AA, Bajaj HC, Bricout H, Monflier E (2012) Catal Sci Technol 2:2273-2278

37. Vangelis C, Bouriazos A, Sotiriou S, Samorski M, Gutsche B, Papadogianakis G (2010) J Catal 274:21-28
38. Ferreira M, Bricout H, Hapiot F, Sayede A, Tilloy S, Monflier E (2008) ChemSusChem 1:631-636

39. Joó F, Kovács J, Kathó Á, Bényei AC, Decuir T, Darensbourg DJ (1998) Inorg Synth 32:1-4

40. Herrmann WA, Kohlpaintner CW (1998) Inorg Synth 32:14-16

41. Gulyás H, Szöllősy Á, Szabó P, Halmos P, Bakos J (2003) Eur J Org Chem 2003:2775-2781

42. Mika LT, Orha L, Farkas N, Horváth IT (2009) Organometallics 28:1593-1596

43. Hansch C, Leo A, Taft RW (1991) Chem Rev 91:165-195

44. Tolman CA (1977) Chem Rev 77:313-348

45. Darensbourg DJ, Bischoff CJ (1993) Inorg Chem 32:47-53

46. Snelders DJM, van Koten G, Klein Gebbink RJM (2011) Chem Eur J 17:42-57

47. Bényei AC, Gulyás H, Ozawa Y, Kimura K, Toriumi K, Kégl T, Bakos J (2007) J Organomet Chem 692:1845-1851

48. Gulyás H, Bényei AC, Bakos J (2004) Inorg Chim Acta 357:3094-3098

49. Moore LR, Western EC, Craciun R, Spruell JM, Dixon DA, O'Halloran KP, Shaughnessy KH (2008) Organometallics 27:576-593

50. Papp G, Kovács J, Bényei AC, Laurenczy G, Nádasdi L, Joó F (2001) Can J Chem 79:635-641

51. Pinell RP, Megerle CA, Manatt SL, Kroon PA (1973) J Am Chem Soc 95:977-978

52. Allen DW, Taylor BF (1982) J Chem Soc Dalton Trans, pp. 51-54

53. Fache E, Santini C, Senocq F, Basset JM (1992) J Mol Catal 72:331-336

54. Hernandez M, Kalck P (1997) J Mol Catal A 116:117-130

55. Ferreira M, Bricout H, Tilloy S, Monflier E (2017) Molecules 22:140

56. Herrmann WA, Kellner J, Riepl H (1990) J Organomet Chem 389:103-128

57. Herrmann WA, Kulpe JA, Kellner J, Riepl H, Bahrmann H, Konkol W (1990) Angew Chem 102:408-414

58. Herrmann WA, Kulpe JA, Kellner J, Riepl H, Bahrmann H, Konkol W (1990) Angew Chem Int Ed Engl 29:391-393

59. Snelders DJM, Yan N, Gan W, Laurenczy G, Dyson PJ (2012) ACS Catal 2:201-207

Publisher's Note Springer Nature remains neutral with regard to jurisdictional claims in published maps and institutional affiliations. 